\title{
Correction to: Human-Nature Relationships and Normative Beliefs Influence Behaviors that Reduce the Spread of Aquatic Invasive Species
}

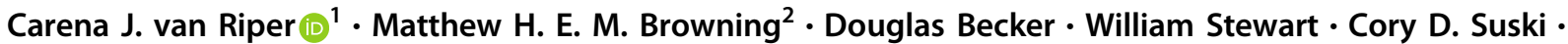 \\ Lara Browning ${ }^{3} \cdot$ Elizabeth Golebie
}

Published online: 20 March 2019

(c) Springer Science+Business Media, LLC, part of Springer Nature 2019

\section{Correction to: Environmental Management}

(2019) 63:69-79;

https://doi.org/10.1007/s00267-018-1111-9

The original article was published with few incorrect contexts.

In Discussion section, fifth sentence of the first paragraph on p. 75 should read as:

In particular, given that the Participant in Nature orientation positively influenced norms and behavior, management agencies that tailor communication strategies to address the co-dependence of people and nature, will be more likely to align with the existing worldviews of anglers included in this study. Our results also indicated that managers should emphasize the physical, emotional, and spritual bonds formed between people and places given that respondents who held these beliefs were less likely to respond to social pressure, and in turn, take action that would minimize the spread of AIS.

The original article can be found online at https://doi.org/10.1007/ s00267-018-1111-9

Carena J. van Riper

cvanripe@illinois.edu

1 Department of Natural Resources and Environmental Sciences, University of Illinois, Urbana, IL, USA

2 Department of Recreation, Sport, and Tourism, University of Illinois, Urbana, IL, USA

3 Office of Recreation and Park Resources, University of Illinois, Urbana, IL, USA 